\title{
Source, Characterization of Indoor Dust PAHs and the Health Risk on Chinese Children*
}

\author{
Xin-qi WANG, Xu LI, Yu-yan YANG, Lin FAN, Xu HAN, Li LI, Hang LIU, Tan-xi GE, Li-qin SU, Xian-liang WANG", \\ Yuan-duo ZHU\# \\ China CDC Key Laboratory of Environment and Population Health, National Institute of Environmental Health, Chinese \\ Center for Disease Control and Prevention, Beijing 100021, China
}

(C) The Author(s) 2021

\begin{abstract}
Summary: Polycyclic aromatic hydrocarbons (PAHs) in indoor dust are one of the common exposure sources for children worldwide. The aim of this study is to explore PAHs pollution status in indoor dust and estimate health risk on Chinese children with big data. Weighted average concentration was used to analyze source and characterization of PAHs in indoor dust based on peer-reviewed literature. According to specific inclusion criteria, 17 studies were included finally to analyze weighted average concentration. The national average concentration of $\sum_{16} \mathrm{PAHs}$ was approximately $25.696 \mu \mathrm{g} / \mathrm{g}$. The highest concentration of $\sum_{16} \mathrm{PAHs}$ was in Shanxi $(2111.667 \mu \mathrm{g} /$ $\mathrm{g})$, and the lowest was in Hong Kong $(1.505 \mu \mathrm{g} / \mathrm{g})$. The concentrations in Shanxi and Guangdong were higher than national level and the over standard rate was $18.18 \%$. The concentrations of individual PAHs varied greatly across the country, and Flu in Shanxi was the highest $(189.400 \mu \mathrm{g} /$ g). The sources of PAHs varied in different regions and combustion processes played a leading role. PAHs exposure through ingestion and dermal contact was more carcinogenic than inhalation. The incremental lifetime cancer risk model indicated that children lived in Shanxi were found in the highest health risk coupled with the highest BaPE concentration $(54.074 \mu \mathrm{g} / \mathrm{g})$. Although PAHs concentrations of indoor dust showed a downward trend from 2005 to 2018, indoor environmental sanitation should be improved with multidisciplinary efforts. Health standard should be possibly established to minimize children exposure to PAHs in indoor dust in China.
\end{abstract}

Key words: indoor dust; polycyclic aromatic hydrocarbons; source; children; China; health risk

Most people spend more than $90 \%$ of their time living indoors usually ${ }^{[1,2]}$, especially infants, the elderly and patients with chronic diseases. Therefore, people may be exposed to indoor pollutants for a long time which may be higher than those of outdoors ${ }^{[3]}$. Indoor dust is considered to be an exposure medium and a global indicator of residential pollution ${ }^{[1,4]}$. Infants and young children are in highest risk since their hand-tomouth habit ${ }^{[5]}$. A large number of epidemiological data

Xin-qi WANG, E-mail: 15032314202@163.com

\#Corresponding authors, Xian-liang WANG, E-mail: wangxianliang@nieh.chinacdc.cn; Yuan-duo ZHU, E-mail: zhuyuanduo@nieh.chinacdc.cn

*This study was supported by the National Natural Science Foundation of China (No. 21976169), the Natural Science Foundation of Beijing, China (No. 8182055), and the Opening Fund of State Key Laboratory of Building Safety and Built Environment, China (No. BSBE2017-09).

Electronic supplementary material The online version of this article (https://doi.org/10.1007/s11596-021-2337-y) contains supplementary material, which is available to authorized users. show that indoor dust exposure is related to human health problems, including cardiovascular diseases, respiratory diseases and eye diseases ${ }^{[6,7]}$. In addition, there is evidence that the harmful health effects may depend on the pollutants in indoor dust ${ }^{[8]}$. Polycyclic aromatic hydrocarbons (PAHs) have been detected as the main toxic components in indoor dust $\mathrm{t}^{[9,10]}$.

PAHs are a class of persistent organic pollutants (POPs) generally existing in environment, consisted of two or more benzene rings. Tobacco smoking, cooking, kerosene burning, and wood burning are common sources of PAHs in indoor environment ${ }^{[11-14]}$. Sixteen PAHs have been given priority to control by the US Environmental Protection Agency (EPA) due to their carcinogenicity and mutagenicity ${ }^{[15]}$. Seven PAHs were classified as possible carcinogens or class 2B human carcinogens ${ }^{[16]}$. Concentration-dependent relationships between organic pollutants, such as PAHs, in indoor dust and human health issues have been established ${ }^{[17,18]}$.

The current researches mainly focus on the sources and pollution of PAHs outdoors and there are 
few studies on indoor PAHs pollution and risk analysis. The objectives of this study are: (1) to determine the concentrations and profiles of PAHs in indoor dust in China; (2) to distinguish the sources of PAHs in indoor dust in China; (3) to assess health risk on Chinese children via inhalation, dust ingestion and dermal contact using the incremental lifetime cancer risk (ILCR) standard model established by US EPA ${ }^{[19]}$; (4) to enrich the research of indoor PAHs in China and to provide basic information for indoor environment and health management of residents.

\section{MATERIALS AND METHODS}

\subsection{Data Sources}

Papers were identified through searching PubMed, Science Direct, Web of Science, China National Knowledge Infrastructure and WanFang online electronic database, using relevant terms for PAHs and indoor dust. The Boolean operators "AND" and "OR" were used to combine topic areas, such as [(indoor) OR (house) OR (residential) OR (residence)] AND [(China) OR (Chinese)] AND (dust) AND (PAHs). A total of 2533 articles were retrieved from January 1975 to December 2020. The flow chart of qualified literature screening process is shown in fig. 1. According to the relevant requirements of this study, articles including raw numeric values of PAHs in indoor dust in China were retained, and review articles were excluded.

\subsection{Inclusion Criteria and Exclusion Criteria}

Inclusion criteria: (1) Research on PAHs concentrations in indoor dust in China; (2) raw numeric of PAHs concentrations in indoor dust can be extracted; (3) the unit of PAHs concentrations can be converted into $\mu \mathrm{g} / \mathrm{g}$.

Exclusion criteria: (1) Research on indoor dust concentration based on simulated model; (2) review articles; (3) research on air detection of airborne dust; (4) research on forced intervention measures during the experiment.

\subsection{Data Standardization}

The types and sample sizes of PAHs involved in published studies are different. Direct calculation of the average concentration will lead to deviation. In order to make the results more accurate, the weighted average concentration is used in this study. The specific formula is shown in (1):

$$
C_{t}=\frac{\sum_{n=1} C_{n} \times N_{n}}{\sum_{n=1} N_{n}}
$$

$C_{n}$ represents the raw concentration of each sample in the original literature; $N_{n}$ represents the sample size in the original literature; $C_{t}$ represents the weighted average concentration of sample.

\subsection{Source Analysis of PAHs}

The diagnostic ratio was used to analyze the

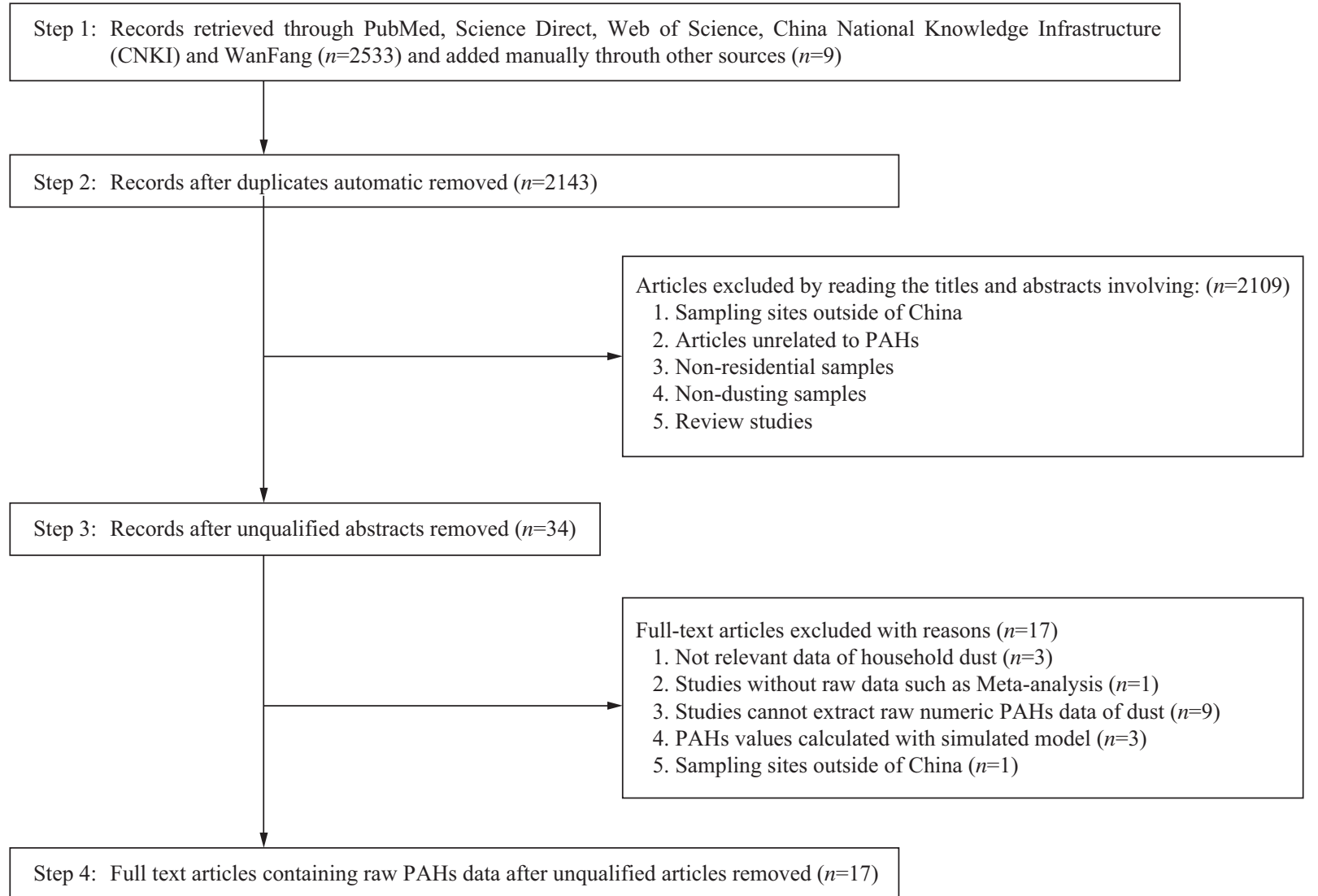

Fig. 1 Flow chart of qualified literature screening 
source of $\mathrm{PAHs}^{[20,21]}$. Different diagnostic ratios indicate specific emission sources ${ }^{[22]}$, such as LMW/ HMW (low molecular weight, 2-3 rings PAHs; high molecular weight, 4-6 rings PAHs), Ant/(Ant+Phe), $\mathrm{Flu} /(\mathrm{Flu}+\mathrm{Pyr}), \mathrm{BaA} /(\mathrm{BaA}+\mathrm{Chr}), \quad \mathrm{IcdP} /(\mathrm{IcdP}+\mathrm{BghiP})$ and $\sum \mathrm{COMB} / \sum \mathrm{PAHs}\left(\sum \mathrm{COMB}\right.$, including Flu, $\mathrm{Pyr}$, $\mathrm{BaA}, \mathrm{Chr}, \mathrm{BbF}, \mathrm{BkF}, \mathrm{BaP}$, IcdP, and BghiP).

\subsection{PAHs Health Risk Assessment}

ILCRs model was used to evaluate the latent cancer risk of exposure to indoor dust ${ }^{[23]}$. Humans expose to indoor dust PAHs via dermal contact, ingestion and inhalation. The ILCR (no unit) is calculated on the basis of three contact routes ${ }^{[23]}$ and the following standard models from the US EPA are used:

$$
\begin{aligned}
& I L C R_{\text {Ingestion }}=\frac{T E Q_{B a P} \times E D \times E F \times I R_{\text {Ingestion }} \times C S F_{\text {Ingestion }} \times\left(\frac{B W}{70}\right)^{\frac{1}{3}}}{B W \times A T \times 10^{6}} \\
& I L C R_{\text {Inhalation }}=\frac{T E Q_{B a P} \times E D \times E F \times I R_{\text {Inhalation }} \times C S F_{\text {Inhalation }} \times\left(\frac{B W}{70}\right)^{\frac{1}{3}}}{B W \times A T \times P E F} \\
& I L C R_{\text {Dermal }}=\frac{T E Q_{B a P} \times E D \times E F \times A F \times S A \times A B S \times C S F_{\text {Dermal }} \times\left(\frac{B W}{70}\right)^{\frac{1}{3}}}{B W \times A T \times 10^{6}}
\end{aligned}
$$

The parameters in the child model for the risk assessment are shown in table S1. TEQ $Q_{B a P}$ represents the summation of $\mathrm{PAH}$ concentrations calculated according to the toxic equivalent factor $(T E F)$ and the toxic equivalent of $\mathrm{BaP}^{[24]}$.

$T E Q_{B a P}$ is calculated by formula (5):

$$
T E Q_{B a P}=\sum_{i=1}^{n}\left(C_{i} \times T E F_{i}\right)
$$

Where $T E Q_{B a P}$ is total toxic equivalent concentration of $\mathrm{BaP}(\mu \mathrm{g} / \mathrm{g}) ; C_{i}$ is the mass concentration of the initial PAHs $(\mu \mathrm{g} / \mathrm{g}) ; T E F_{i}$ is its toxic equivalency factor $^{[24]}$ (Nap, Acy, Ace, Fl, Phe, Flu and Pyr are 0.001. Ant, $\mathrm{Chr}$ and BghiP are 0.01 . BaA, BbF, BkF and IcdP are 0.1 . $\mathrm{BaP}$ is 1 . DahA is 5$)^{[22]}$.

$\mathrm{BaP}$ is the first and strongest discovered environmental carcinogenic PAHs, and other HWM PAHs (BaA, BbF, BkF, IcdP and DahA) also have carcinogenic potential. The $\mathrm{BaP}$ equivalent $(\mathrm{BaPE})$ is a useful index to assess the potential toxicity of PAHs in sediments, which can be calculated according to the following equation $(6)^{[25,26]}$.

$$
\begin{aligned}
\mathrm{BaPE}= & \mathrm{BaA} \times 0.06+(\mathrm{BbF}+\mathrm{BkF}) \times 0.07+\mathrm{BaP}+\mathrm{DahA} \times \\
& 0.60+\mathrm{IcdP} \times 0.08
\end{aligned}
$$

\subsection{Statistical Analysis}

Excel2010 was used for data entry, data sorting and chart drawing, and SPSS21.0 was used for statistical analysis. Non-parametric Kruskal-Wallis $H$ test was used for analyzing the difference in the level of risk among the three exposure routes. Spearman correlation analysis was used for analyzing the relationship between $\mathrm{BaPE}$ and $I L C R_{\text {Ingestion, }}$ $I L C R_{\text {Inhalation }}, I L C R_{\text {Dermal }}$.

\section{RESULTS}

\subsection{General Characteristics of Articles Included}

A total of 17 articles $^{[5,8,27-41]}$ from 2007 to 2020 were included in this study through screening of qualified literature. Some critical information including provinces in China was collected. Samples were collected from 2005 to 2018 (2005, 2007, 2008, 2011, 2012, 2013, 2014 and 2018).

In 1976, the US EPA identified 16 kinds of PAHs as the priority control objects ${ }^{[15]}$. These are naphthalene (Nap, 2 rings), acenaphthene (Ace, 3 rings), acenaphthylene (Acy, 3 rings), fluorene (Fl, 3 rings), phenanthrene (Phe, 3 rings), anthracene (Ant, 3 rings), fluoranthene (Flu, 4 rings), pyrene (Pyr, 4 rings), chrysene (Chr, 4 rings), benz[a]anthracene (BaA, 4 rings), benzo[b]fluoranthene (BbF, 5 rings), benzo[k]fluoranthene (BkF, 5 rings), benzo[a]pyrene (BaP, 5 rings), dibenz[a, $\mathrm{h}]$ anthracene (DahA, 5 rings), benzo[g, h, i]perylene (BghiP, 6 rings) and indeno[1, 2, 3-cd]pyrene (IcdP, 6 rings). A total of 16 different kinds of PAHs were presented in previous literature. One study examined 18 kinds of PAHs, the other 6 studies examined 15 kinds of PAHs (table 1). The highest detection rate was $99.88 \%$ of Flu, Pyr and Chr. The lowest detection rate was $97.30 \%$ of Ant.

\subsection{Characteristics of PAHs Concentrations in $\mathbf{1 1}$ Provinces}

The concentration of different PAHs varied widely across the country (fig. 2). The concentration of Flu in Shanxi province was the highest $(189.400 \mu \mathrm{g} / \mathrm{g})$ and the concentrations of Ace, Acy and Fl were relatively

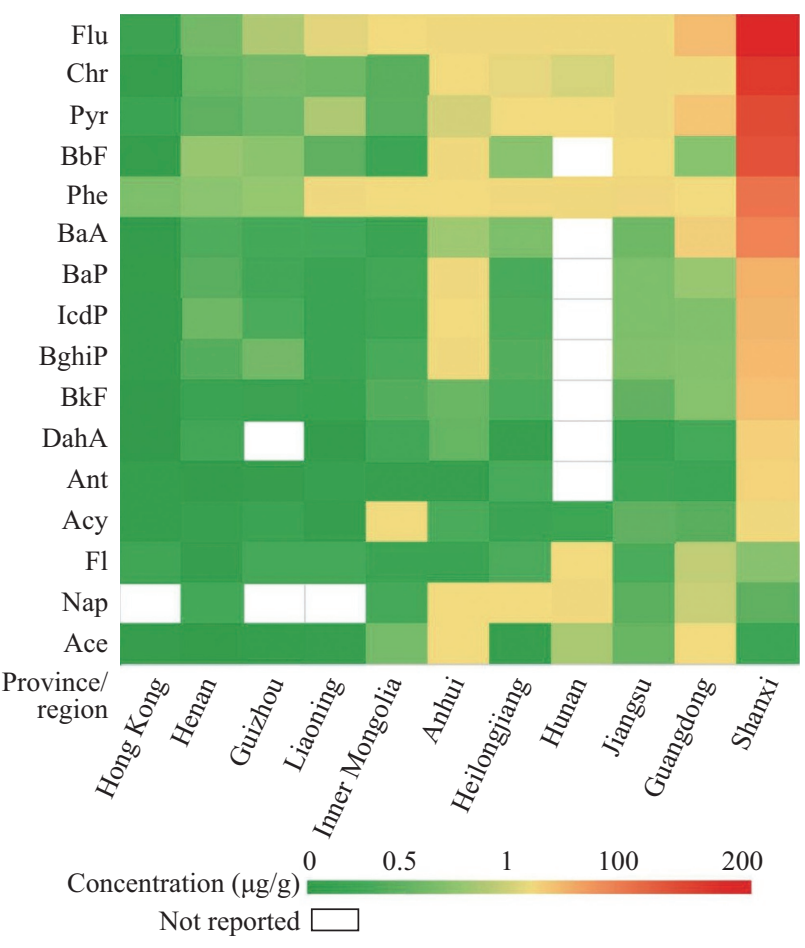

Fig. 2 Heat map of indoor dust concentration of 16 PAHs in 11 provinces/region 


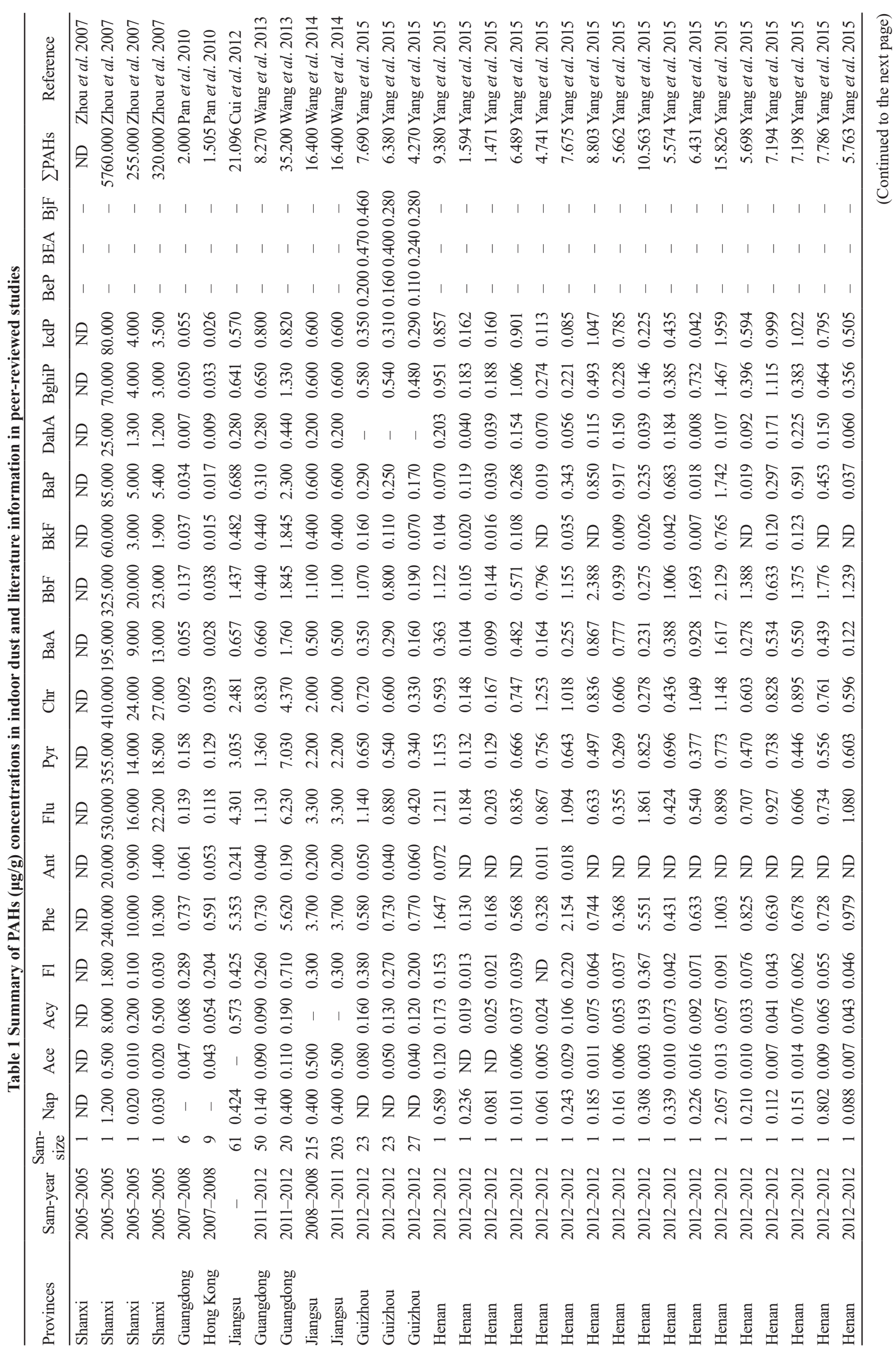




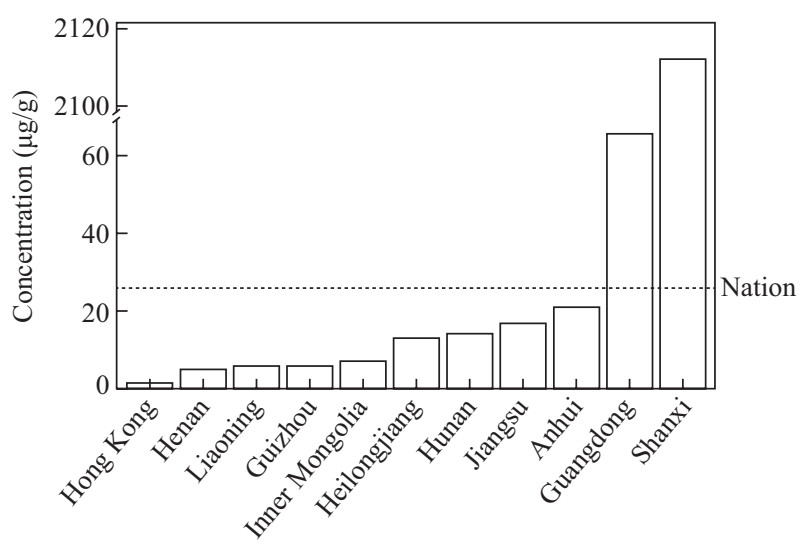

Fig. 3 Comparison of $\sum_{16} \mathrm{PAHs}$ concentrations in 11 provinces/ region with national concentrations

low. Fig. 3 shows the analysis of the weighted average concentration of indoor dust $\sum_{16}$ PAHs. The highest residential $\sum_{16}$ PAHs concentration was in Shanxi $(2111.667 \mu \mathrm{g} / \mathrm{g})$, and the lowest was in Hong Kong $(1.505 \mu \mathrm{g} / \mathrm{g})$. The national average concentration of $\sum_{16} \mathrm{PAHs}$ was $25.696 \mu \mathrm{g} / \mathrm{g}$ in this study. Only the concentration in Shanxi and Guangdong was higher than the national level, and over standard rate was $18.18 \%$. The composition profiling of PAHs was different in 11 provinces/region (fig. 4). There were mainly 4 rings PAHs (83.13\% and 59.22\%) in Guangdong and Shanxi, respectively, 3 rings PAHs $(63.53 \%)$ in Hong Kong, 3 and 4 rings PAHs $(77.97 \%, 67.21 \%$ and $60.92 \%)$ in Liaoning, Jiangsu and Inner Mongolia, respectively.

\subsection{Temporal Differences of Sample-weighted Mean Concentration of Indoor Dust PAHs}

PAHs concentration in Shanxi province from one study was significantly higher than that in other regions. Therefore, the data of Shanxi province (2005) were removed in data analysis to avoid information errors. The weighted average concentrations of different rings and different kinds of PAHs were calculated and the trend of their variation over time was plotted (figs. 5 and 6). Four rings PAHs were the highest in each time period, especially in 2005-2010 (1.876 $\mu \mathrm{g} / \mathrm{g}$ in fig. 5A) and rings showed a downward trend with time (fig. 5B). $\sum_{16} \mathrm{PAHs}$ were also the highest $(15.442 \mu \mathrm{g} / \mathrm{g})$ in 2005-2010 but the lowest in 2016-2020 (6.000 $\mu \mathrm{g} / \mathrm{g})$. In 2005-2010, the concentration of Phe was the highest $(3.501 \mu \mathrm{g} / \mathrm{g})$, DahA was the lowest in 2016-2020 (0.021 $\mu \mathrm{g} / \mathrm{g}$ ) in fig. 6. Nap, Acy, BaA, BkF, DahA and BghiP were higher in 2011-2015 than in 2005-2010. Overall, the concentrations of PAHs showed a downward trend.

\subsection{Source Analysis of PAHs}

HMW PAHs are mainly originated from hightemperature combustion process and LMW PAHs are chiefly originated from low or moderate temperature combustion $^{[42]}$. Table S2 shows the principle of PAHs source classification. In general, combustion induces the production of relatively higher concentrations of 


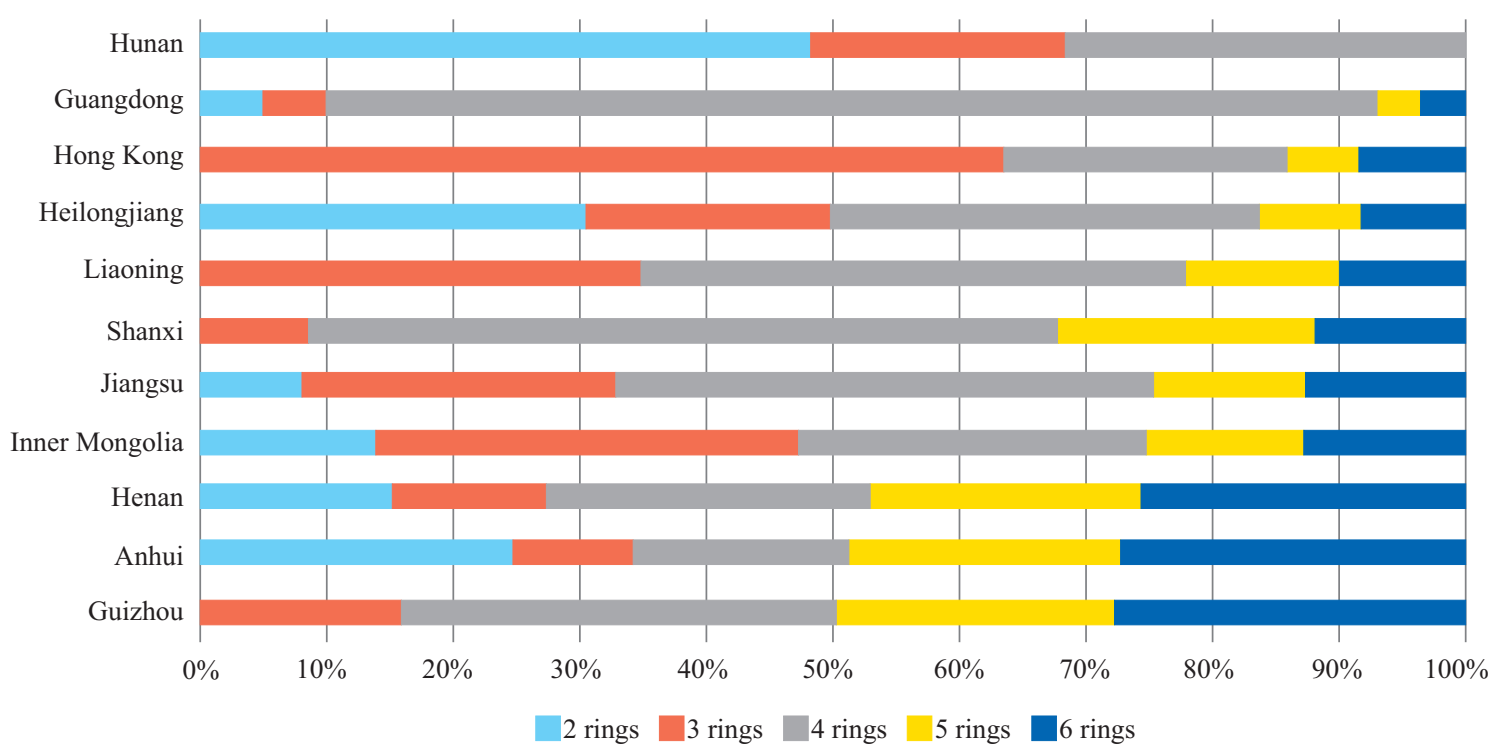

Fig. 4 PAHs composition profiling characteristics of indoor dust in 11 provinces/region
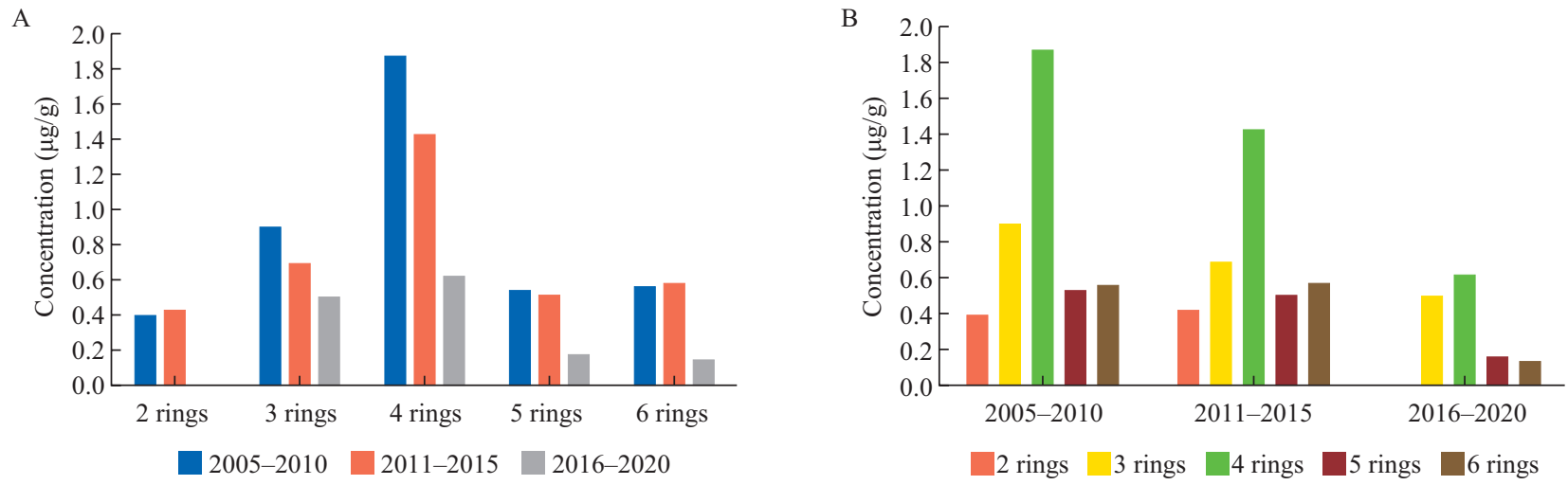

Fig. 5 Temporal differences of sample-weighted mean concentration of PAHs with different rings The data in Shanxi province are not included.

$\sum \mathrm{COMB}$; therefore, a large proportion of $\sum \mathrm{COMB}$ is a characteristic of PAHs that originated from combustion $\operatorname{processes}^{[43]}$.

Table S3 and fig. 7 show diagnostic ratios of PAHs in indoor dust in 11 provinces/region. The ratios of the $\sum \mathrm{COMB} / \sum \mathrm{PAHs}$ ranged from 0.294 to 0.919 , which inferred that the PAHs in samples mainly originated from combustion processes. In Henan (fig. 7B, 7E and 7F), Shanxi (fig. 7B), Anhui (fig. 7F), Heilongjiang (fig. 7F) and Guangdong (fig. 7F), PAHs may originate from combustion of coal, grasses, and wood. In Hong Kong (fig. 7B), Inner Mongolia (fig. 7E), Guizhou (fig. $7 \mathrm{E})$, PAHs may originate from petroleum combustion.

\subsection{Health Risk Assessment of PAHs Exposure}

Human exposure to PAHs may occur via ingestion, inhalation, and dermal contact ${ }^{[44]}$. The most sensitive subpopulation is young children because of their handto-mouth activity, whereby contaminated dust can be readily ingested ${ }^{[45]}$. The ILCR formula with default parameters was used to identify the different exposure pathways for children to evaluate the health risk. Table 2 presents the calculated ILCR values. Previous studies indicated that an ILCR value of $10^{-6}$ generally represented an acceptable level, an ILCR value from $10^{-6}$ to $10^{-4}$ indicated a potential human carcinogenic risk, and an ILCR value higher than $10^{-4}$ indicated a serious carcinogenic risk ${ }^{[46,47]}$. The calculated results indicated that PAHs exposure posed a potential human carcinogenic risk in Shanxi, Guangdong and Anhui. The ILCR value was the highest in Shanxi province and the lowest in Hunan province. And the cancer risk levels via ingestion, dermal contact and inhalation were $5.301 \times 10^{-8}$ vs. $2.572 \times 10^{-4}, 6.608 \times 10^{-8}$ vs. $3.207 \times 10^{-4}$, and $1.028 \times 10^{-12}$ vs. $4.988 \times 10^{-9}$, respectively. Since the level of risk among the different exposure pathways was non-normal distribution, the non-parametric KruskalWallis $H$ test was performed to compare the difference. The results indicated that the health risk level was different among different exposure routes. All these results indicated that ingestion and dermal contact exposure was more carcinogenic than inhalation ${ }^{[22]}$.

The concentration of $\mathrm{BaPE}$ ranged from 0.030 $\mu \mathrm{g} / \mathrm{g}$ to $54.074 \mu \mathrm{g} / \mathrm{g}$. Spearman correlation analysis revealed there was a positive correlation between BaPE 

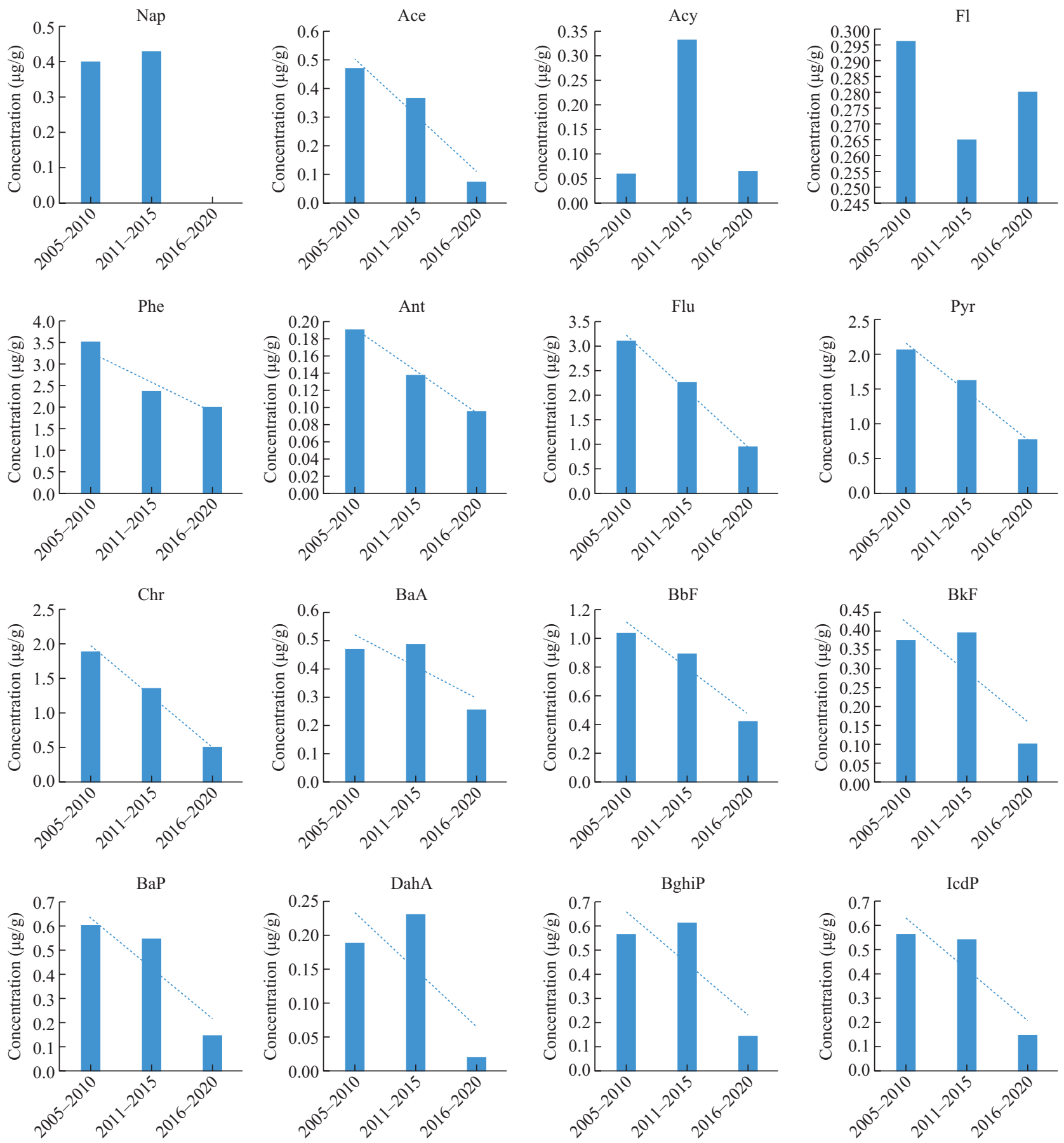

Fig. 6 Temporal differences of sample-weighted mean concentration of 16 kinds of PAHs The data in Shanxi province are not included.

Table 2 Carcinogenic risk values of PAHs $(\mu \mathrm{g} / \mathrm{g})$ in indoor dust from different exposure routes

\begin{tabular}{lcccc}
\hline Provinces/region & $T E Q_{\text {BaP }}(\mu \mathrm{g} / \mathrm{g})$ & $I L C R_{\text {Ingestion }}$ & $I L C R_{\text {Inhalation }}$ & $I L C R_{\text {Dermal }}$ \\
\hline Hunan & 0.022 & $5.301 \times 10^{-8}$ & $1.028 \times 10^{-12}$ & $6.608 \times 10^{-8}$ \\
Hong Kong & 0.075 & $1.849 \times 10^{-7}$ & $3.584 \times 10^{-12}$ & $2.304 \times 10^{-7}$ \\
Liaoning & 0.354 & $8.706 \times 10^{-7}$ & $1.688 \times 10^{-11}$ & $1.085 \times 10^{-6}$ \\
Guizhou & 0.381 & $9.388 \times 10^{-7}$ & $1.820 \times 10^{-11}$ & $1.170 \times 10^{-6}$ \\
Heilongjiang & 0.857 & $2.111 \times 10^{-6}$ & $4.093 \times 10^{-11}$ & $2.631 \times 10^{-6}$ \\
Inner Mongolia & 1.481 & $3.647 \times 10^{-6}$ & $7.071 \times 10^{-11}$ & $4.546 \times 10^{-6}$ \\
Jiangsu & 1.522 & $3.746 \times 10^{-6}$ & $7.264 \times 10^{-11}$ & $4.670 \times 10^{-6}$ \\
Henan & 1.681 & $4.139 \times 10^{-6}$ & $8.025 \times 10^{-11}$ & $5.159 \times 10^{-6}$ \\
Guangdong & 3.288 & $8.096 \times 10^{-6}$ & $1.570 \times 10^{-10}$ & $1.009 \times 10^{-5}$ \\
Anhui & 4.943 & $1.217 \times 10^{-5}$ & $2.360 \times 10^{-10}$ & $1.517 \times 10^{-5}$ \\
Shanxi & 104.490 & $2.572 \times 10^{-4}$ & $4.988 \times 10^{-9}$ & $3.207 \times 10^{-4}$ \\
\hline
\end{tabular}



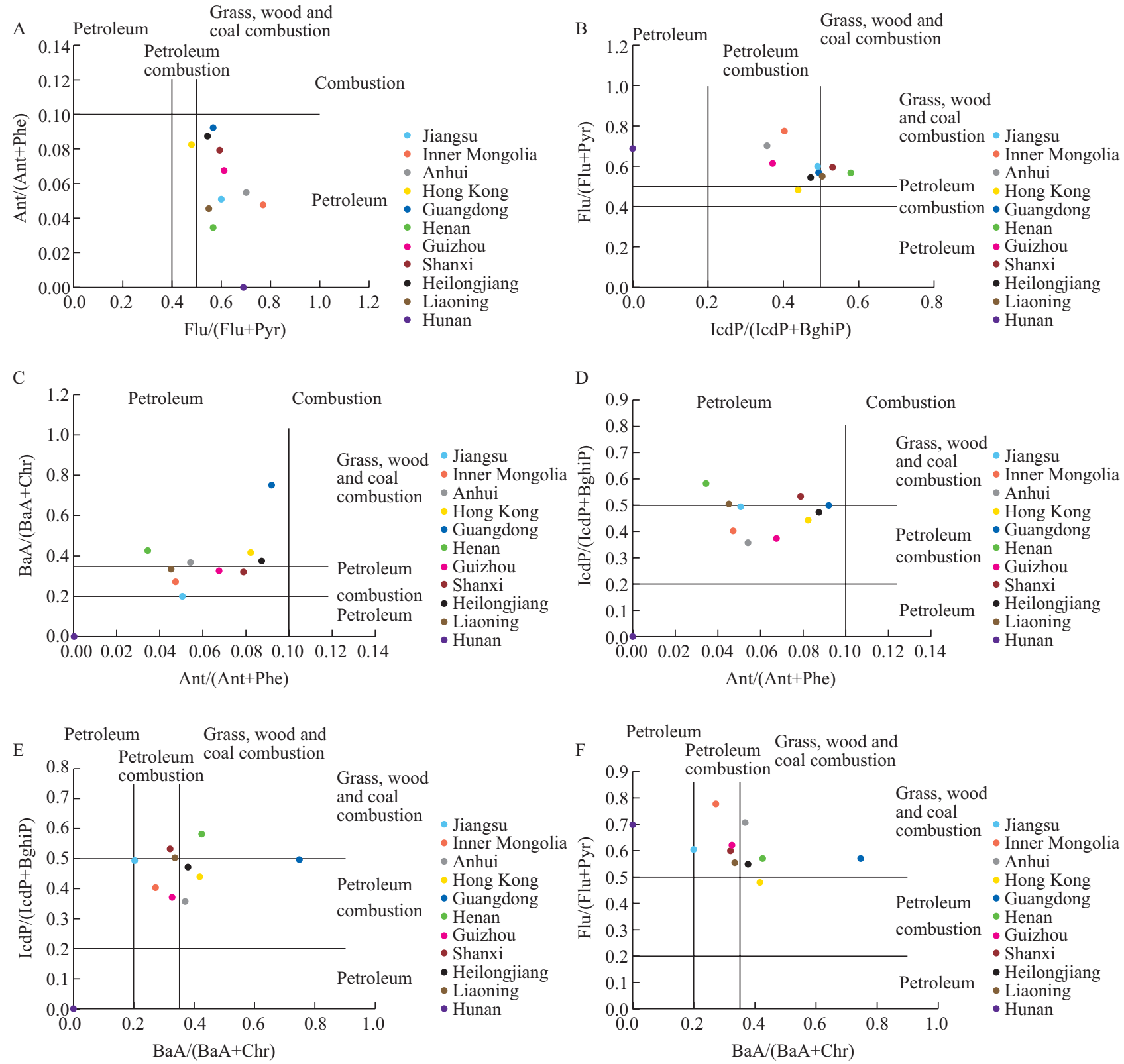

Fig. 7 PAHs source analysis based on the diagnostic ratios in 11 provinces/region

and ILCR $R_{\text {Ingestion, }} I L C R_{\text {Inhalation, }}$ ILCR $R_{\text {Dermal }}$ Therefore, there was the highest health risk level in Shanxi where $\mathrm{BaPE}$ concentration was also at the highest level (fig. 8). There were low BaPE concentration and low health risk level in Hunan.

\section{DISCUSSION}

This article reviewed the literature on PAHs contamination in indoor dust in 11 provinces across China. PAHs concentrations varied greatly across the country, and they were the highest in Shanxi and the lowest in Hong Kong. The concentrations in Shanxi and Guangdong were higher than national level in this study. The source of PAH varies in different regions, but almost originates from combustion processes.
PAHs exposure through ingestion and dermal contact were more carcinogenic than inhalation. Shanxi had highest BaPE concentration and health risk level.

In China, few papers evaluated the PAHs contamination in dust, especially in indoor dust $\mathrm{t}^{[48]}$. While in the other countries, a large number of papers were related to indoor dust PAHs, little is known about the impact of indoor pollution sources on personal PAHs exposure ${ }^{[49]}$. In recent years, the number of published articles related to indoor dust of PAHs increased exponentially. However, in this paper, 17 included studies were published from 2007 to 2020, and there were no data records before 2007, indicating that indoor dust PAHs draw more attention just in recent years.

Sixteen PAHs have been prioritized for control by 


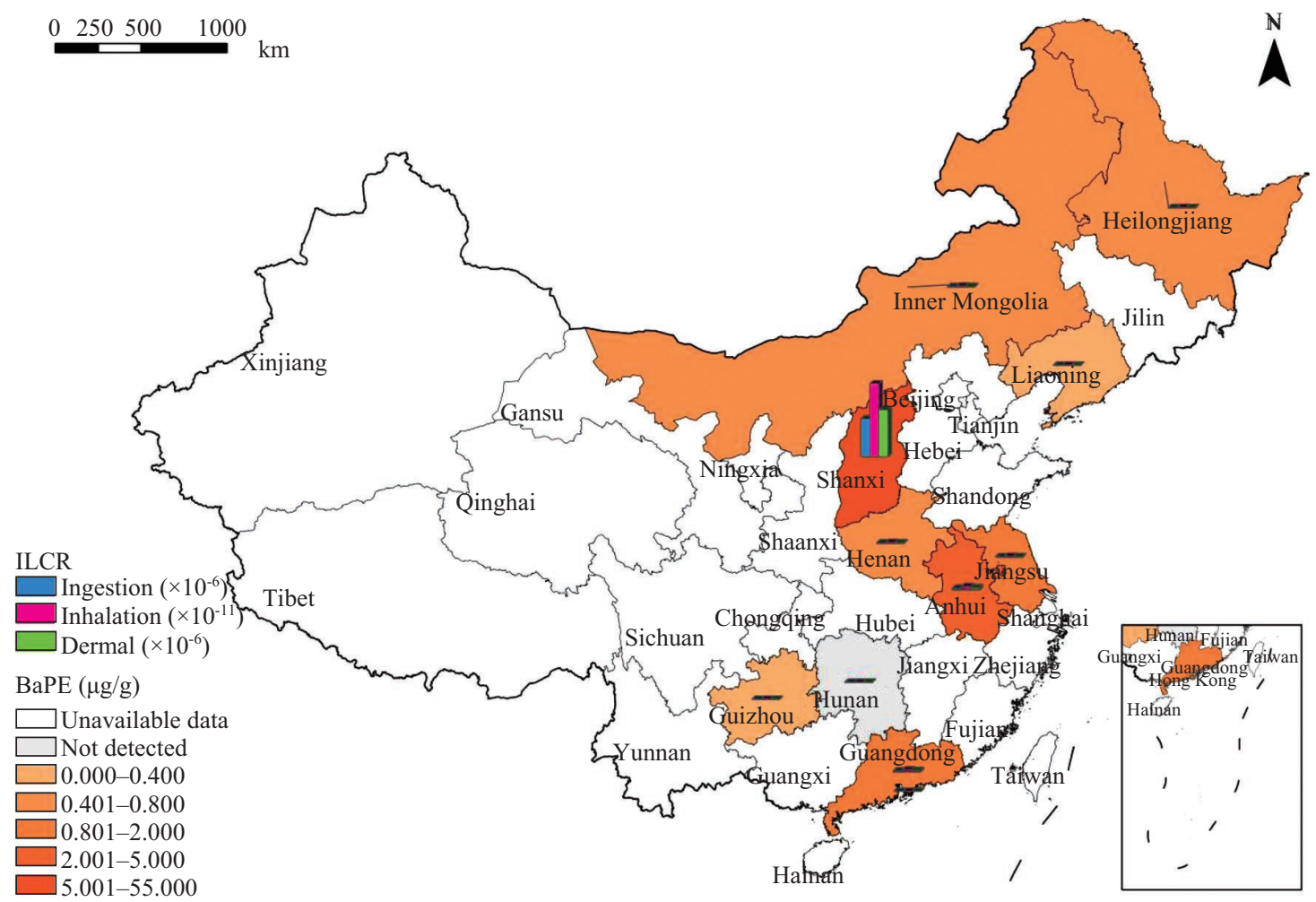

Fig. 8 Geographical distribution of BaPE exposure and ILCR values of three exposure pathways in 11 provinces/region

the US EPA because of their carcinogenic and mutagenic properties $^{[15]}$. These 16 PAHs were detected and analyzed in many studies. The concentrations of Ace, Acy and Fl were relatively low in 11 provinces/region and Flu in Shanxi was the highest. The concentration of PAHs varied greatly across the country, with the lowest average concentration in Hong Kong and the highest in Shanxi. Shanxi is the leading province in coal production in China, and coal is commonly used indoors for cooking and heating in this region ${ }^{[27]}$. The major products of thermal decomposition of coal include PAHs as well as related nitrogen- and sulfur-containing PAHs ${ }^{[50,51]}$. The national average concentration of $\sum_{16}$ PAHs was approximately $25.696 \mu \mathrm{g} / \mathrm{g}$ in this study. It was higher than those of settled house dust (SHD) samples collected from homes in urban areas of San Diego County, CA, USA $(0.163-4.390 \mu \mathrm{g} / \mathrm{g} \text {; median, } 0.990 \mu \mathrm{g} / \mathrm{g})^{[14]}$ but was lower than those in Ohio, USA $(11.1-513 \mu \mathrm{g} / \mathrm{g}$; median, $47.4 \mu \mathrm{g} / \mathrm{g})^{[9]}$, and Texas, USA $(1.12-341 \mu \mathrm{g} / \mathrm{g}$; median, $28.8 \mu \mathrm{g} / \mathrm{g})^{[10]}$. The PAHs concentrations of indoor dust tended to decrease with time approximately. It may be because people's awareness of environmental protection has been raised, and the national governance of indoor and outdoor environment has been done. However, due to the lack of consecutive surveillance data of PAHs, the actual changing trend of PAHs can't be observed.

PAHs diagnostic ratios have been used to identify different sources that contribute PAHs to environmental samples ${ }^{[52]}$. PAHs in most samples mainly originate from combustion processes. Our results indicated that petroleum combustion was the origin of PAHs in Hong Kong, Inner Mongolia, and Guizhou. PAHs may originate from combustion of coal, grasses, and wood in Henan, Anhui, Shanxi, Guangdong and Heilongjiang. The PAHs source of indoor dust in other provinces may originate from complex sources. Vehicle restriction and switching clean energy can effectively reduce indoor PAHs pollution levels. However, this method is not an exact method of distinguishing sources and only provides a qualitative estimation ${ }^{[53]}$. If we want to identify the sources of PAHs in indoor dust more clearly, we need more data to analyze or use other analytical methods such as Principal Component Analysis. Gustafson et al[54] concluded that the concentration of PAHs of households using wood burning for heating in winter in Sweden was significantly higher. Ansari et $a^{[55]}$ found that indoor PAHs mainly originated from cooking fuel in rural India such as wood. Abbasi et a ${ }^{[56]}$ showed that indoor PAHs may come from petroleum in developing and oil-rich countries such as Iran. So the source of PAHs in indoor dust is related to the local industrial structure and the lifestyle of residents.

$\mathrm{BaP}$ is the first environmental carcinogen to be discovered with highly carcinogenic PAHs. The BaPE value is often used as an index to evaluate the toxicity of PAHs. BaPE concentration was the highest in Shanxi which is the leading province in coal production in China and provides as much as one-third of China's coal $^{[27]}$. High temperature combustion process (such as vehicular exhaust, mining processing activities) ${ }^{[35]}$ and 
living habits (such as cooking, heating, smoking) ${ }^{[57]}$ may make contributions to the high BaPE concentration.

At present, there is not a perfect standard for health risk assessment of PAHs in indoor dust in China. The results of exposure assessment of PAHs in house dust to children is quantitative and therefore is much more comparable than health risk of different endpoints. The ILCR model is widely used now ${ }^{[23]}$. The ILCR is taken as an ensign to identify the age-specific potential cancer risks in the study of human exposure to environmental PAH pollution sources ${ }^{[54,58]}$. Results indicate that dermal contact and ingestion exposure are more carcinogenic than inhalation ${ }^{[22]}$. Dermal contact is the most dominant exposure route, which is easily to be ignored $^{[34]}$. Due to behavioral characteristics such as hand-to-mouth activities and food handling, non-dietary inhalation of contaminants is potentially the main route of exposure for children. Dermal contact and ingestion exposures are also important route for children and are associated with behaviors such as crawling on the floor and contact with dirt and grass ${ }^{[59]}$. In addition, early development of organ, nervous, and immune systems may enhance the carcinogens sensitivity in children ${ }^{[56]}$. However, the results calculated based on ILCRs model still have certain limitations. Exposure by ingestion, inhalation, or dermal contact is according to the size of the dust particles. Li et $a l^{[39]}$ found that inhalation was the main exposure route for LWM PAHs, and ingestion was the major route for HWM PAHs. Most current research is unaware of this problem. So, the accuracy of the assessment results will be affected to some extent ${ }^{[37]}$. Therefore, relevant standards and models for health risk assessment of PAHs in indoor dust need to be improved to be more suitable for the actual conditions of indoor environment in China, and provide basic information for residents' protection.

There are several limitations in this paper. Although we searched literature of nearly 45 years, raw numeric concentrations of PAHs in indoor dust in other provinces were lack to estimate national concentration of PAHs in indoor dust. In addition, different instruments and methods were chosen to analyze dust samples in the 17 studies, resulting in different detection limits of PAHs. PAHs were detected with different methods including gas chromatography-mass spectrometry ${ }^{[28,33,35,37-39]}$, high performance liquid chromatography ${ }^{[27,29,30,34]}$, gas chromatograph equipped with a flame ionization detector $^{[31]}$. Moreover, the sampling requirements or sampling sites were not consistent in these papers. The influence of these confounding factors existed and would bring some bias on the results in this study to some extent.

In conclusion, this study analyzed public literature in the last 45 years to explore PAHs pollution characterization in indoor dust nationwide. PAHs are widely found in indoor dust. There are differences in
PAHs concentrations (they were the highest in Shanxi province) and sources in indoor dust at different provinces. Although there is a downward trend of PAHs over time and the indoor environment condition has been greatly improved, its negative impact can't be ignored. Especially children as sensitive subpopulation, efforts should be conducted to prevent and control their dermal contact and ingestion exposures. There are rare articles similar to this study. Therefore, in our opinion, the study on PAHs in indoor dust from Chinese households should be further strengthened.

\section{Open Access}

This article is licensed under a Creative Commons Attribution 4.0 International License https://creativecommons.org/licenses/by/4.0/), which permits use, sharing, adaptation, distribution and reproduction in any medium or format, as long as you give appropriate credit to the original author(s) and the source, provide a link to the Creative Commons licence, and indicate if changes were made. The images or other third party material in this article are included in the article's Creative Commons licence, unless indicated otherwise in a credit line to the material. If material is not included in the article's Creative Commons licence and your intended use is not permitted by statutory regulation or exceeds the permitted use, you will need to obtain permission directly from the copyright holder. To view a copy of this licence, visit http://creativecommons. org/licenses/by/4.0/.

\section{Conflict of Interest Statement}

The authors declare that they have no conflict of interest.

\section{REFERENCES}

1 Butte W, Heinzow B. Pollutants in house dust as indicators of indoor contamination. Rev Environ Contam Toxicol, 2002,175:1-46

2 Graham SE, McCurdy T. Developing meaningful cohorts for human exposure models. J Expo Anal Environ Epidemiol, 2004,14(1):23-43

3 Hwang HM, Park EK, Young TM, et al. Occurrence of endocrine-disrupting chemicals in indoor dust. Sci Total Environ, 2008,404(1):26-35

4 Lioy PJ, Freeman NC, Millette JR. Dust: a metric for use in residential and building exposure assessment and source characterization. Environ Health Perspect, 2002,110(10):969-983

5 Wang BL, Pang ST, Zhang XL, et al. Levels and neurodevelopmental effects of polycyclic aromatic hydrocarbons in settled house dust of urban dwellings on preschool-aged children in Nanjing, China. Atmos Pollut Res, 2014,5(2):292-302

6 Gereda JE, Leung DY, Thatayatikom A, et al. Relation between house-dust endotoxin exposure, type $1 \mathrm{~T}$-cell development, and allergen sensitisation in infants at high risk of asthma. Lancet, 2000,355(9216):1680-1683

7 Hansel NN, Breysse PN, McCormack MC, et al. A longitudinal study of indoor nitrogen dioxide levels and respiratory symptoms in inner-city children with 
asthma. Environ Health Perspect, 2008,116(10):14281432

8 Xiang P, Liu RY, Sun HJ, et al. Molecular mechanisms of dust-induced toxicity in human corneal epithelial cells: Water and organic extract of office and house dust. Environ Int, 2016,92-93:348-356

9 Maertens RM, Bailey J, White PA. The mutagenic hazards of settled house dust: a review. Mutat Res, 2004,567(2-3):401-425

10 Mahler BJ, Metre PC, Wilson JT, et al. Coal-tar-based parking lot sealcoat: an unrecognized source of PAH to settled house dust. Environ Sci Technol, 2010,44(3):894900

11 Derudi M, Gelosa S, Sliepcevich A, et al. Emission of air pollutants from burning candles with different composition in indoor environments. Environ Sci Pollut Res Int, 2014,21(6):4320-4330

12 Shen G, Wang W, Yang Y, et al. Emissions of PAHs from indoor crop residue burning in a typical rural stove: emission factors, size distributions, and gas-particle partitioning. Environ Sci Technol, 2011,45(4):12061212

$13 \mathrm{Lv} \mathrm{J}, \mathrm{Zhu} \mathrm{L}$. Effect of central ventilation and air conditioner system on the concentration and health risk from airborne polycyclic aromatic hydrocarbons. J Environ Sci (China), 2013,25(3):531-536

14 Hoh E, Hunt RN, Quintana PJ, et al. Environmental tobacco smoke as a source of polycyclic aromatic hydrocarbons in settled household dust. Environ Sci Technol, 2012,46(7):4174-4183

15 Ontiveros-Cuadras JF, Ruiz-Fernández AC, SanchezCabeza JA, et al. Recent history of persistent organic pollutants (PAHs, PCBs, PBDEs) in sediments from a large tropical lake. J Hazard Mater, 2019,368:264-273

16 U.S. Environmental Protection Agency. 2006. Integrated Risk Information System. http://www.epa.gov/iris

17 Meeker JD, Cooper EM, Stapleton HM, et al. Urinary metabolites of organophosphate flame retardants: temporal variability and correlations with house dust concentrations. Environ Health Perspect, 2013,121(5): 580-585

18 Wei GL, Li DQ, Zhuo MN, et al. Organophosphorus flame retardants and plasticizers: sources, occurrence, toxicity and human exposure. Environ Pollut, 2015,196: $29-46$

19 U.S. EPA (1991) Risk Assessment Guidance for Superfund: Volume I-Human Health Evaluation Manual (Part B, Development of Risk-based Preliminary Remediation Goals). 92857-01B. Washington, D. C: Office of Emergency and Remedial Response

20 Kang Y, Cheung KC, Wong MH. Polycyclic aromatic hydrocarbons (PAHs) in different indoor dusts and their potential cytotoxicity based on two human cell lines. Environ Int, 2010,36(6):542-547

21 Long Y, Dai T, Wu Q. Sources and distribution of polycyclic aromatic hydrocarbons in street dust from the Chang-Zhu-Tan Region, Hunan, China. Environ Monit Assess, 2013,185(2):1377-1390

22 Shen M, Liu G, Yin $\mathrm{H}$, et al. Distribution, sources and health risk of PAHs in urban air-conditioning dust from Hefei, East China. Ecotoxicol Environ Saf, 2020,194:110442
23 Wang W, Huang M, Kang Y, et al. Polycyclic aromatic hydrocarbons (PAHs) in urban surface dust of Guangzhou, China: Status, sources and human health risk assessment. Sci Total Environ, 2011,409(21):45194527

24 Nisbet IC, LaGoy PK. Toxic equivalency factors (TEFs) for polycyclic aromatic hydrocarbons (PAHs). Regul Toxicol Pharmacol, 1992,16(3):290-300

25 Liu WX, Dou H, Wei ZC, et al. Emission characteristics of polycyclic aromatic hydrocarbons from combustion of different residential coals in North China. Sci Total Environ, 2009,407(4):1436-1446

26 Zhang Y, Guo CS, Xu J, et al. Potential source contributions and risk assessment of PAHs in sediments from Taihu Lake, China: comparison of three receptor models. Water Res, 2012,46(9):3065-3073

27 Naufal Z, Zhou GD, McDonald T, et al. Genotoxicity of organic extracts of house dust from Shanxi, China. J Toxicol Environ Health A, 2007,70(24):2080-2088

28 Pan SH, Lin T, Li J, et al. Concentration and distribution of organic matter and polycyclic aromatic hydrocarbons (PAHs) on window glass surface. Zhongguo Huanjing Kexue (Chinese), 2010,30(8):1021-1025

29 Cui Y, Liu M, Chen YJ, et al. Levels and influence factors of polycyclic aromatic hydrocarbons in urban house dust of Nanjing. Nanjing Yike Daxue Xuebao (Chinese), 2012,32(09):1328-1333

30 Wang W, Wu F, Zheng J, et al. Risk assessments of PAHs and $\mathrm{Hg}$ exposure via settled house dust and street dust, linking with their correlations in human hair. J Hazard Mater, 2013,263(2):627-637

31 Wang BL, Pang ST, Zhang Q. Levels of common semivolatile organic compounds in settled house dust of urban dwellings. Zhongguo Gonggong Weisheng (Chinese), 2014, 30(07):931-936

32 Yang Q, Chen H, Li B. Polycyclic aromatic hydrocarbons (PAHs) in indoor dusts of Guizhou, southwest of China: status, sources and potential human health risk. PLoS One, 2015,10(2):e0118141

33 Yang ZZ, Li YF, Fan J. Polycyclic aromatic hydrocarbons in deposited bedroom dust collected from Xinxiang, a fast developing city in North China. Environ Monit Assess, 2015,187(1):4150

34 Kang Y, Shao D, Li N, et al. Cancer risk assessment of human exposure to polycyclic aromatic hydrocarbons (PAHs) via indoor and outdoor dust based on probit model. Environ Sci Pollut Res Int, 2015,22(5):34513456

35 Li FS, Han C, Zhou BH, et al. Distribution and source analysis of polycyclic aromatic hydrocarbons in indoor dust from Anhui province, China. Zhongguo Huanjing Kexue (Chinese), 2016,36(02):363-369

36 Zhou HJ, Fan QY, Mu RG, et al. Characteristics and sources polycyclic aromatic hydrocarbons in Baotou residential dust. Huanjing Huaxue (Chinese), 2017, 36(6):1312-1319

37 Cao ZG, Zhao LC, Shi YM, et al. Pollution and exposure characteristics of polycyclic aromatic hydrocarbons in indoor dust in Xinxiang, China. Huanjing Huaxue (Chinese), 2017,36(3):463-471

38 Zhang T, Mu S, Fan QH. Monitoring and health risk assessment of polycyclic aromatic hydrocarbons in 
residential area around a chemical enterprise. Zhongguo Huanjing Jiance (Chinese), 2019,35(5):79-86

39 Li HL, Liu LY, Zhang ZF, et al. Semi-volatile organic compounds in infant homes: Levels, influence factors, partitioning, and implications for human exposure. Environ Pollut, 2019,251:609-618

40 Yang Y, Wang Y, Tan F, et al. Pet hair as a potential sentinel of human exposure: Investigating partitioning and exposures from OPEs and PAHs in indoor dust, air, and pet hair from China. Sci Total Environ, 2020,745: 140934

41 Luo K, Zeng D, Kang Y, et al. Dermal bioaccessibility and absorption of polycyclic aromatic hydrocarbons (PAHs) in indoor dust and its implication in risk assessment. Environ Pollut, 2020,264:114829

42 Han B, Ding X, Bai Z, et al. Source analysis of particulate matter associated polycyclic aromatic hydrocarbons (PAHs) in an industrial city in northeastern China. J Environ Monit, 2011,13(9):2597-2604

43 Hwang HM, Wade TL, Sericano JL. Concentrations and source characterization of polycyclic aromatic hydrocarbons in pine needles from Korea, Mexico, and United States. Atmos Environ, 2003,37(16):2259-2267

44 Jones-Otazo HA, Clarke JP, Diamond ML, et al. Is house dust the missing exposure pathway for PBDEs? An analysis of the urban fate and human exposure to PBDEs. Environ Sci Technol, 2005,39(14):5121-5130

45 Xia Z, Duan X, Qiu W, et al. Health risk assessment on dietary exposure to polycyclic aromatic hydrocarbons (PAHs) in Taiyuan, China. Sci Total Environ, 2010, 408(22):5331-5337

46 Kamal A, Malik RN, Martellini T, et al. Cancer risk evaluation of brick kiln workers exposed to dust bound PAHs in Punjab province (Pakistan). Sci Total Environ, 2014,493:562-570

47 Chen SC, Liao CM. Health risk assessment on human exposed to environmental polycyclic aromatic hydrocarbons pollution sources. Sci Total Environ, 2006,366(1):112-123

48 Barro R, Regueiro J, Llompart M, et al. Analysis of industrial contaminants in indoor air: part 1. Volatile organic compounds, carbonyl compounds, polycyclic aromatic hydrocarbons and polychlorinated biphenyls. J Chromatogr A, 2009,1216(3):540-566

49 Choi H, Spengler J. Source attribution of personal exposure to airborne polycyclic aromatic hydrocarbon mixture using concurrent personal, indoor, and outdoor measurements. Environ Int, 2014,63:173-181
50 Mumford JL, Li X, Hu F, et al. Human exposure and dosimetry of polycyclic aromatic hydrocarbons in urine from Xuan Wei, China with high lung cancer mortality associated with exposure to unvented coal smoke. Carcinogenesis, 1995,16(12):3031-3036

51 Oña-Ruales JO, Ruiz-Morales Y, Wise SA. Identification and quantification of seven fused aromatic rings $\mathrm{C}_{26} \mathrm{H}_{14}$ peri-condensed benzenoid polycyclic aromatic hydrocarbons in a complex mixture of polycyclic aromatic hydrocarbons from coal tar. J Chromatogr A, 2016,1442:83-93

52 Chen HY, Teng YG, Wang JS. Source apportionment of polycyclic aromatic hydrocarbons (PAHs) in surface sediments of the Rizhao coastal area (China) using diagnostic ratios and factor analysis with nonnegative constraints. Sci Total Environ, 2012,414:293-300

53 Singh KP, Malik A, Kumar R, et al. Receptor modeling for source apportionment of polycyclic aromatic hydrocarbons in urban atmosphere. Environ Monit Assess, 2008,136(1-3):183-196

54 Gustafson P, Ostman C, Sällsten G. Indoor levels of polycyclic aromatic hydrocarbons in homes with or without wood burning for heating. Environ Sci Technol, 2008,42(14):5074-5080

55 Ansari FA, Khan AH, Patel DK, et al. Indoor exposure to respirable particulate matter and particulate-phase PAHs in rural homes in North India. Environ Monit Assess, 2010,170(1-4):491-497

56 Abbasi S, Keshavarzi B. Source identification of total petroleum hydrocarbons and polycyclic aromatic hydrocarbons in $\mathrm{PM}_{10}$ and street dust of a hot spot for petrochemical production: Asaluyeh County, Iran. Sustain Cities Soc, 2019,45:214-230

57 Zhu LZ, Liu YJ, Matsushita Hidetsuru. Pollution survey and source analysis of polycyclic aromatic hydrocarbons in the indoor air. Huanjing Kexue Xuebao (Chinese), 2001,21(1):64-68

58 Zhao Z, Zhang L, Cai Y, et al. Distribution of polycyclic aromatic hydrocarbon (PAH) residues in several tissues of edible fishes from the largest freshwater lake in China, Poyang Lake, and associated human health risk assessment. Ecotoxicol Environ Saf, 2014,104:323-331

59 Black K, Shalat SL, Freeman NC, et al. Children's mouthing and food-handling behavior in an agricultural community on the US/Mexico border. J Expo Anal Environ Epidemiol, 2005,15(3):244-251

(Received Feb. 1, 2021; accepted Mar. 12, 2021) 